\title{
Analisis Pengendalian Persediaan Bahan Baku Kerupuk Mentah Potato dan Kentang Keriting Menggunakan Metode Economic Order Quantity (EOQ)
}

\author{
Jainuril Efendi ${ }^{1}$, Khoirul Hidayat ${ }^{* 1}$, dan Raden Faridz ${ }^{1}$ \\ 1) Program Studi Teknologi Industri Pertanian Fakultas Pertanian Univesitas Trunojoyo Madura \\ Jl. Raya Telang, Kamal Bangkalan PO BOX 2 Madura 69162, Indonesia
}

DOI: 10.20961/performa.18.2.35418

\begin{abstract}
Abstrak
Peningkatan sektor industri pangan dari tahun ke tahun membuat pelaku industri pangan mengalami persaingan yang lebih ketat. Dalam era ketatnya persaingan industri pangan ini, pengendalian persediaan bahan baku di PT. Surya Indah Food Multirasa masih mengalami kendala kekurangan bahan baku potato dan kentang keriting disetiap tahun, yang berimbas kehilangan penjualan. Penelitian ini dilakukan untuk mengetahui jumlah pemesanan yang tepat dalam setiap pembelian bahan baku sehingga tidak terjadi kekurangan bahan baku, dengan biaya persediaan yang lebih hemat. Penelitian ini menggunakan metode Economic Order Quantity (EOQ) untuk menganalisis pengendalian persediaan bahan baku potato dan kentang keriting antara menggunakan kebijakan perusahaan dengan EOQ. Analisis perhitungan EOQ diikuti dengan melakukan analisis safety stock (SS), maximum inventory (MI), total inventory cost (TIC) dan reorder point (ROP) sehingga diketahui persediaan yang optimal bagi perusahaan. Hasil analisis EOQ menunjukkan metode EOQ lebih hemat dibanding kebijakan perusahaan dengan selisih rata-rata TIC pada bahan baku potato ialah Rp. 856.124 dan kentang keriting sebesar Rp. 1.065.989. Nilai EOQ rata-rata pada bahan baku potato ialah $344 \mathrm{~kg}$ sedangkan kentang keriting $234 \mathrm{~kg}$. Selanjutnya nilai SS rata-rata pada bahan baku potato ialah $75 \mathrm{~kg}$ sedangkan kentang keriting $35 \mathrm{~kg}$, dan ROP rata-rata pada bahan baku potato ialah $123 \mathrm{~kg}$ sedangkan kentang keriting $58 \mathrm{~kg}$. Dalam penelitian ini juga dilakukan peramalan menggunakan metode Winter's untuk mengetahui data permintaan pada tahun 2019 sehingga diketahui peramalan nilai EOQ pada tahun 2019. Hasil perhitungan EOQ menggunakan data peramalan tahun 2019 pada bahan baku potato ialah 371 kg sedangkan kentang keriting $258 \mathrm{~kg}$.
\end{abstract}

Kata kunci: EOQ, Pengendalian Persediaan; Peramalan; Reorder Point; Safety Stock

\begin{abstract}
The increase in the food industrial sector over the year making food producers experience tighter competition. In this era of intense competition in the food industry, raw material inventory control in PT. Surya Indah Food Multirasa is still facing a problem of lacking raw material in potatoes and curly potatoes every year, which affects in sale loss. This study is conducted to find out the precise amount of order in every raw material purchase, so there is no lack of raw material, at a lower cost. This study uses the Economic Order Quantity (EOQ) method for analyzing raw material control for potatoes and curly potatoes. Comparing the uses of company policy and EOQ. EOQ analysis calculation followed by conducting safety stock (SS) analysis, maximum inventory (MI) analysis, Total Inventory Cost (TIC) analysis, and reorder point (ROP) analysis, therefore, optimal stock for the company can be discovered. The result of EOQ analysis showed that the EOQ method is more efficient than company policy with TIC average difference for potato's raw material that is $R p .856 .124$ and curly potatoes raw material that is Rp. 1.065.989. The average EOQ value of potato's raw material is $344 \mathrm{~kg}$ while curly potatoes are $234 \mathrm{~kg}$. Next is the average SS value for potato raw material is $75 \mathrm{~kg}$ while curly potatoes are $35 \mathrm{~kg}$, and the average ROP value for potato raw is $123 \mathrm{~kg}$ while curly potatoes are $58 \mathrm{~kg}$. This research also performs forecasting using Winter's method so that data demand for the year of 2019 can be discovered. The forecast result with the EOQ method for the year 2019 is $371 \mathrm{~kg}$ for potato's raw material and $258 \mathrm{~kg}$ for curly potatoes.
\end{abstract}

Keywords: EOQ; Stock Control; Forecasting; Reorder Point; Safety Stock

\section{Pendahuluan}

Pengendalian persediaan bahan baku merupakan serangkaian hal dalam menentukan tingkat persediaan, waktu pembelian dan jumlah persediaan yang harus disediakan (Herjanto 2015). Pengendalian persediaan bahan baku bertujuan agar biaya persediaan dapat efisien, salah satu caranya adalah dengan melakukan

*Korespondensi : irul_ie@yahoo.co.id 
pembelian yang tepat sesuai rencana produksi sehingga tidak mengalami kekurangan dan kelebihan dalam persediaan bahan baku (Renta et al 2013). Mengendalikan persediaan juga bertujuan menjaga suatu perusahaan agar terhindar dari pembelian secara kecil-kecilan yang mengakibatkan biaya pemesanan menjadi besar (Sampeallo 2012). Menurut Nasution (2008) Persediaan adalah sumber daya menganggur yang menunggu proses lebih lanjut. Dengan adanya perencanaan persediaan, perusahaan dapat memenuhi pesanan pembeli secara cepat dan tepat, serta tidak akan menimbulkan persediaan berlebih yang dapat mengakibatkan penggunaan dana tidak efisien (Darmawan et al., 2015)

Metode Economic Order Quantity (EOQ) adalah salah satu teknik manajemen persediaan dengan mempertimbangkan biaya penyimpanan dan biaya pemesanan. Apabila total biaya tersebut diturunkan, maka akan diperoleh kuantitas pemesanan yang optimal (Mardiyanto 2008). Biaya penyimpanan diestimasikan berdasarkan rata-rata penyimpanan barang selama satu tahun (Indroprasto 2012). Dengan menggunakan metode EOQ maka dapat dihitung pula safety stock, maximum inventory dan juga reorder point yang optimal bagi perusahaan sehingga menghindari terjadinya kekurangan maupun kelebihan persediaan.

PT. Surya Indah Food Multirasa merupakan perusahaan makanan yang memproduksi 3 jenis kategori produk yaitu, produk penggorengan (potato, kentang keriting, makaroni dan gadung), gilingan (pastel mini), ovenan (nastar, lidah kucing). Pengendalian persediaan bahan baku pada PT. Surya Indah Food Multirasa masih dilakukan dengan cara yang sederhana, sehingga seiring dengan tingginya permintaan produk menyebabkan terjadinya kekurangan persediaan bahan baku yang menghambat proses produksi. Pada tahun 2018 PT. Surya Indah Food Multirasa mengalami kekurangan bahan baku di bulan Juni (bertepatan bulan Ramadhan dan Hari Raya Idul Fitri). Hal serupa juga terjadi pada tahun 2017 dan 2016, dimana PT. Surya Indah Food Multirasa mengalami kekurangan bahan baku pada waktu yang sama halnya dialami pada tahun 2018. Kekurangan persediaan bahan baku terjadi pada bahan baku produk Potato dan Kentang Keriting, yang mana produk tersebut banyak diminati.

Oleh karena itu untuk mendukung tercapainya ketersediaan bahan baku tepat dengan biaya persediaan yang lebih efisien di PT. Surya Indah Food Multirasa, perlu dilakukan penelitian tentang analisis pengendalian persediaan bahan baku dengan menggunakan metode EOQ. Karena metode EOQ mempertimbangkan baik biaya operasi maupun biaya finansial serta menentukan kuantitas pemesanan yang akan meminimumkan biaya persediaan secara keseluruhan (Margaretha 2007), dan metode ini merupakan penentuan jumlah pesanan paling ekonomis yang dapat dilakukan apabila persediaan bahan baku bergantung lebih pada satu pemasok sehingga perlu dipertimbangkan jumlah pembelian sesuai dengan kebutuhan proses produksi (Sugiono 2009).

\section{Metode Penelitian}

Penelitian dilakukan di PT. Surya Indah Food Multirasa yang terletak di Jl. Raden Patah No.61, Kepanjen, Kec. Jombang, Kabupaten Jombang. Jenis data yang digunakan dalam penelitian ini meliputi data kebutuhan bahan baku, biaya pemesanan, biaya penyimpanan, dan lead time. Ada beberapa variabel analisis perhitungan untuk mendukung penggunaan metode EOQ, yaitu sebagai berikut:

\section{Perhitungan EOQ dan TIC}

Perhitungan EOQ dan TIC dilakukan untuk mengetahui nilai EOQ dan TIC pada pengendaliaan persediaan bila menggunakan kebijakan perusahaan maupun metode EOQ. Perhitungan tersebut dilakukan menggunakan rumus sebagai berikut:

Rumus yang digunakan dalam menentukan nilai EOQ adalah:

$$
Q^{*}=\sqrt{2(\mathrm{D} . \mathrm{S}) /(\mathrm{H})}
$$

Rumus yang digunakan dalam menentukan nilai TIC adalah:

$$
\mathrm{TIC}=\left(\frac{\mathrm{D}}{\mathrm{Q}} \mathrm{xS}\right)+\left(\frac{\mathrm{Q}}{2} \mathrm{xH}\right)
$$

Dimana:

$Q^{*} \quad=Q^{*}$ adalah EOQ, yaitu jumlah pemesanan dengan biaya total persediaan paling rendah.

TIC = Biaya Total Persediaan (Total Inventory Cost)

$\mathrm{D} \quad=$ Jumlah kebutuhan barang.

$\mathrm{S} \quad$ = Biaya pemesanan atau biaya setup.

$\mathrm{H} \quad$ = Biaya penyimpanan.(Herjanto 2015)

\section{Perhitungan Safety Stock}

Safety stock (Persediaan Pengaman) diadakan untuk mengantisipasi terjadinya kondisi kehabisan persediaan yang tak terduga pada pengendalian persediaan perusahaan. Habisnya suatu persediaan pada 
perusahaan akan mengakibatkan hilangnya penjualan (Mahatmyo 2014). Perhitungan safety stock dapat diketahui dengan melakukan perkalian antara faktor pengaman dengan standar deviasi dengan rumus sebagai berikut:

$$
\begin{aligned}
& S S=\mathrm{Z} \times \sigma \\
& \sigma=\sqrt{\frac{\sum(X-\bar{x})^{2}}{n}}
\end{aligned}
$$

Dimana:

$$
\begin{aligned}
& S S=\text { Safety Stock (Persediaan Pengaman). } \\
& \sigma=\text { Standar deviasi permintaan selama waktu tenggang. } \\
& \mathrm{Z}=\text { Faktor pengaman. } \\
& \mathrm{n}=\text { Jumlah data. } \\
& \mathrm{x}=\text { Jumlah kebutuhan bahan. } \\
& \overline{\mathrm{x}}=\text { Rata-rata kebutuhan bahan. (Herjanto 2015) }
\end{aligned}
$$

3. Perhitungan Reorder Point

Reorder Point (ROP) menurut Herjanto (2015) merupakan jumlah persediaan yang menunjukkan saat harus dilakukan pemesanan ulang barang sehingga barang yang dipesan datang tepat waktu. Titik ini menandakan bahwa pembelian harus segera dilakukan untuk menggantikan persediaan yang telah digunakan.Rumus yang digunakan untuk menghitung ROP adalah:

$$
\mathrm{ROP}=\mathrm{d} \mathrm{x} \mathrm{L}+\mathrm{SS}
$$

Dimana:

$$
\begin{array}{ll}
\mathrm{ROP} & =\text { Titik pemesanan ulang. } \\
\mathrm{d} & =\text { Tingkat kebutuhan per unit waktu. } \\
\mathrm{L} & =\text { Waktu tenggang. (Herjanto 2015) }
\end{array}
$$

\section{Perhitungan Maximum Inventory}

Menurut Assauri (2008) Maximum Inventory (Persediaan Maksimum) merupakan batasan jumlah persediaan yang paling besar yang sebaiknya diterapkan pada perusahaan. Hal itu diperlukan oleh setiap perusahaan agar jumlah persediaan yang disimpan digudang tidak berlebihan sehingga tidak terjadi pemborosan modal kerja. Rumus yang digunakan untuk menghitung Maximum Inventory adalah:

$$
\text { Maximum inventory }(\mathrm{MI})=\text { Safety Stock }+ \text { EOQ }
$$

\section{Dimana:}

$$
\begin{aligned}
& \text { Safety Stock: Persediaan pengaman. } \\
& \text { EOQ : jumlah pembelian optimal. (Assauri 2008) }
\end{aligned}
$$

\section{Hasil dan Pembahasan}

Selama ini, PT. Surya Indah Food Multirasa melakukan pengendalian persediaan bahan baku dengan metode yang cukup sederhana yaitu pemesanan didasarkan pada jumlah permintaan terhadap produk dan pemesanan dilakukan pada saat bahan baku mendekati habis. Hal itu mengakibatkan terjadinya kekurangan persediaan bahan baku potato dan kentang keriting pada saat permintaan terhadap kedua produk tersebut mengalami peningkatan.

\section{Perhitungan Jumlah Pesanan menurut Kebijakan Perusahaan}

Pada penelitian kali ini dilakukan perhitungan EOQ menggunakan data 3 tahun terakhir yaitu mulai tahun 2016-2018. Berikut merupakan data kebutuhan bahan baku selama tahun 2016-2018.

Tabel 1. Kebutuhan Bahan Baku Potato dan Kentang Keriting

\begin{tabular}{cccc}
\hline \multirow{2}{*}{ Tahun } & Bahan Baku & $\begin{array}{c}\text { Kebutuhan Bahan Baku } \\
\text { per Tahun }(\text { Kg) }\end{array}$ & $\begin{array}{c}\text { Frekuensi } \\
\text { Pemesanan (kali) }\end{array}$ \\
\hline \multirow{2}{*}{2016} & Kentang Keriting & 1.065 & 24 \\
\cline { 2 - 4 } & Potato & 2.270 & 24 \\
\hline \multirow{2}{*}{2017} & Kentang Keriting & 1.100 & 24 \\
\cline { 2 - 4 } & Potato & 2.345 & 24 \\
\hline \multirow{2}{*}{2018} & Kentang Keriting & 1.210 & 24 \\
\cline { 2 - 4 }
\end{tabular}

Pemesanan bahan baku dilakukan sebanyak 24 kali dalam setahun, atau dilakukan setiap 2 minggu sekali. 
Tabel 2. Biaya Pemesanan

\begin{tabular}{cccc}
\hline Tahun & Produk & Total Biaya Per Tahun $(\mathbf{R p})$ & Biaya per Pesan $(\mathbf{R p})$ \\
\hline \multirow{2}{*}{2016} & & & $(\mathbf{S})$ \\
\hline \multirow{2}{*}{2017} & & & $\frac{\text { Total biaya per tahun }}{\text { Frekuensi pemesasan }}$ \\
\cline { 2 - 4 } & & & 64.388 \\
\cline { 2 - 4 } & Kentang Keriting & 1.545 .307 & 64.388 \\
\cline { 2 - 4 } & Kotato & 1.545 .307 & 69.521 \\
\hline \multirow{2}{*}{2018} & Kentang Keriting & 1.668 .515 & 69.521 \\
\cline { 2 - 4 } & Potato & 1.668 .515 & 74.529 \\
\cline { 2 - 4 } & Pentang Keriting & 1.788 .698 & 74.529 \\
\hline
\end{tabular}

Biaya yang termasuk dalam biaya pemesanan meliputi biaya penggunaan telepon dan biaya administrasi (biaya bongkar muat barang).

Tabel 3.Biaya Penyimpanan

\begin{tabular}{lcc}
\hline Tahun & Produk & Biaya Simpan per Unit (Rp) \\
\hline & & $(\mathbf{H})$ \\
\hline \multirow{2}{*}{2016} & & $\frac{\text { Total biaya per tahun }}{\text { Jumlah kebutuhan }}$ \\
\cline { 2 - 3 } & & $3.015,98$ \\
\cline { 2 - 3 } 2017 & Kentang Keriting & $2.829,97$ \\
\cline { 2 - 3 } & Potato & $2.928,48$ \\
\cline { 2 - 3 } & Kentang Keriting & $2.747,41$ \\
\hline \multirow{2}{*}{2018} & Potato & $2.665,63$ \\
\cline { 2 - 3 } & Kentang Keriting & $2.682,26$ \\
\hline
\end{tabular}

Biaya yang termasuk dalam biaya penyimpanan meliputi biaya listrik, biaya pengawasan dan perawatan pada gudang.

Tabel 4. Perhitungan jumlah pesanan menurut Kebijakan Perusahaan

\begin{tabular}{ccccc}
\hline \multirow{2}{*}{ Tahun } & Produk & $\begin{array}{c}\text { Kebutuhan Bahan Baku } \\
\text { per Tahun }(\text { Kg) }\end{array}$ & $\begin{array}{c}\text { Frekuensi } \\
\text { (Kali) }\end{array}$ & $\begin{array}{c}\text { Jumlah Pesanan Rata-rata per } \\
\text { Pesanan }(\mathbf{K g})\end{array}$ \\
\hline \multirow{2}{*}{2016} & $(\mathbf{D})$ & $(\mathbf{f})$ & $\mathbf{Q}=\left(\frac{\boldsymbol{D}}{\boldsymbol{f}}\right)$ \\
\hline \multirow{2}{*}{2017} & Kentang Keriting & 1.065 & 24 & 44 \\
\cline { 2 - 5 } & Potato & 2.270 & 24 & 95 \\
\cline { 2 - 5 } & Kentang Keriting & 1.100 & 24 & 46 \\
\hline \multirow{2}{*}{2018} & Potato & 2.345 & 24 & 98 \\
\cline { 2 - 5 } & Kentang Keriting & 1.210 & 24 & 50 \\
\hline
\end{tabular}

Berdasarkan tabel diatas, dapat diketahui bahwa kebutuhan pembelian bahan baku yang dilakukan oleh PT. Surya Indah Food Multirasa setiap satu kali pesan tidak terlalu berbeda jauh dari tahun 2016 hingga 2018. Hal itu dikarenakan jumlah permintaan bahan baku tidak mengalami kenaikan yang signifikan dan jumlah frekuensi pemesanan yang selalu sama dalam setiap tahunnya. 
Tabel 5. Perhitungan TIC menurut Kebijakan Perusahaan

\begin{tabular}{ccccc}
\hline \multirow{2}{*}{ Tahun } & Produk & $\begin{array}{c}\text { Total Biaya Pemesanan } \\
(\mathbf{R p})\end{array}$ & $\begin{array}{c}\text { Total Biaya } \\
\text { Penyimpanan (Rp) }\end{array}$ & $\begin{array}{c}\text { Biaya Total Persediaan } \\
\text { (TIC) (Rp) }\end{array}$ \\
\hline \multirow{2}{*}{2016} & $\mathbf{\frac { \boldsymbol { Q } } { \boldsymbol { Q } } \boldsymbol { x } \boldsymbol { S }}$ & $\frac{\boldsymbol{Q}}{\mathbf{2}} \boldsymbol{x} \boldsymbol{H}$ & $\left\{\frac{\boldsymbol{D}}{\boldsymbol{Q}} \boldsymbol{x}\right\}+\left\{\frac{\boldsymbol{Q}}{\mathbf{2}} \boldsymbol{x} \boldsymbol{H}\right\}$ \\
\hline \multirow{2}{*}{2017} & $\begin{array}{c}\text { Kentang } \\
\text { Keriting }\end{array}$ & 1.545 .307 & 66.917 & 1.612 .224 \\
\cline { 2 - 5 } & Potato & 1.545 .307 & 133.834 & 1.679 .141 \\
\hline \multirow{2}{*}{2018} & $\begin{array}{c}\text { Kentang } \\
\text { Keriting }\end{array}$ & 1.668 .515 & 67.111 & 1.735 .626 \\
\cline { 2 - 5 } & Potato & 1.668 .515 & 134.222 & 1.802 .737 \\
\cline { 2 - 5 } & $\begin{array}{l}\text { Kentang } \\
\text { Keriting }\end{array}$ & 1.788 .698 & 67.196 & 1.855 .894 \\
\hline
\end{tabular}

Nilai biaya total persediaan yang harus dikeluarkan PT. Surya Indah Food Multirasa setiap tahunnya mengalami kenaikan, hal tersebut dikarenakan adanya perubahan biaya pemesanan dan biaya penyimpanan pada setiap tahun.

\section{Perhitungan EOQ dan TIC}

Tabel 6. Perhitungan jumlah pesanan menurut metode EOQ

\begin{tabular}{|c|c|c|c|c|c|c|}
\hline Tahun & Produk & $\begin{array}{c}\text { Kebutuhan Bahan } \\
\text { Baku per Tahun } \\
\text { (Kg) }\end{array}$ & $\begin{array}{l}\text { Biaya Penyimpanan } \\
\text { per Unit (Rp) }\end{array}$ & $\begin{array}{c}\text { Biaya } \\
\text { Pemesanan } \\
(\mathbf{R p}) \\
\end{array}$ & $\begin{array}{c}\text { Jumlah } \\
\text { Pesanan } \\
\text { (Kg) } \\
\end{array}$ & $\begin{array}{l}\text { Frekuens } \\
\text { i (kali) }\end{array}$ \\
\hline & & & & & $\begin{array}{r}\mathrm{EOQ}= \\
2 X D X S\end{array}$ & $\begin{array}{ll}f & \\
& D\end{array}$ \\
\hline & & D & H & $\mathbf{S}$ & $\sqrt{\frac{H D O D}{H}}$ & $=\overline{E O Q}$ \\
\hline \multirow{2}{*}{2016} & $\begin{array}{l}\text { Kentang } \\
\text { Keriting } \\
\end{array}$ & 1.065 & $3.015,98$ & 64.388 & 213 & 5 \\
\hline & Potato & 2.270 & $2.829,97$ & 64.388 & 321 & 7 \\
\hline \multirow[t]{2}{*}{2017} & $\begin{array}{l}\text { Kentang } \\
\text { Keriting }\end{array}$ & 1.100 & $2.928,48$ & 69.521 & 229 & 5 \\
\hline & Potato & 2.345 & $2.747,41$ & 69.521 & 344 & 7 \\
\hline \multirow[t]{2}{*}{2018} & $\begin{array}{l}\text { Kentang } \\
\text { Keriting }\end{array}$ & 1.210 & $2.665,63$ & 74.529 & 260 & 5 \\
\hline & Potato & 2.405 & $2.682,26$ & 74.529 & 366 & 7 \\
\hline
\end{tabular}

Berdasarkan tabel diatas, biaya pemesanan mengalami peningkatan setiap tahunnya, karena harga bahan bakar minyak mengalami kenaikan sehingga biaya pemesanan juga mengalami keniakan. Jumlah pesanan semakin banyak jika dibandingkan dengan kebijakan perusahaan, sedangkan untuk frekuensi pemesanan lebih sedikit jika dibandingkan kebijakan perusahaan dari 24 kali dalam setahun menjadi 5 dan 7 kali dalam setahun.

Tabel 7. Perhitungan Biaya Total Persediaan menurut metode EOQ

\begin{tabular}{|c|c|c|c|c|}
\hline Tahun & Produk & $\begin{array}{c}\text { Total Biaya Pemesanan } \\
(\mathrm{Rp})\end{array}$ & $\begin{array}{c}\text { Total Biaya } \\
\text { Penyimpanan (Rp) }\end{array}$ & Biaya Total Persediaan (Rp) \\
\hline & & $\frac{D}{E O Q} \times S$ & $\frac{E O Q}{2} x H$ & $\begin{array}{l}\left\{\frac{D}{E O Q} \times S\right\} \\
+\left\{\frac{E O Q}{2} \times H\right\}\end{array}$ \\
\hline \multirow[t]{2}{*}{2016} & $\begin{array}{l}\text { Kentang } \\
\text { Keriting }\end{array}$ & 321.570 & 321.570 & 643.141 \\
\hline & Potato & 454.769 & 454.769 & 909.538 \\
\hline \multirow{2}{*}{2017} & $\begin{array}{l}\text { Kentang } \\
\text { Keriting }\end{array}$ & 334.628 & 334.628 & 669.256 \\
\hline & Potato & 473.235 & 473.235 & 946.471 \\
\hline \multirow{2}{*}{2018} & $\begin{array}{l}\text { Kentang } \\
\text { Keriting }\end{array}$ & 346.690 & 346.690 & 693.379 \\
\hline & Potato & 490.293 & 490.293 & 980.586 \\
\hline
\end{tabular}


Tabel 8. Penghematan Biaya Persediaan

\begin{tabular}{cccccc}
\hline \multirow{2}{*}{ Tahun } & Produk & Kebijakan perusahaan (Rp) & EOQ (Rp) & Penghematan(Rp) & Persen \\
\hline \multirow{2}{*}{2016} & Kentang Keriting & 1.612 .224 & 643.141 & 969.084 & $60,11 \%$ \\
\cline { 2 - 6 } & Potato & 1.679 .141 & 909.538 & 769.603 & $45,83 \%$ \\
\hline \multirow{2}{*}{2017} & Kentang Keriting & 1.735 .626 & 669.256 & 1.066 .370 & $61,44 \%$ \\
\cline { 2 - 6 } & Potato & 1.802 .737 & 946.471 & 856.266 & $47,50 \%$ \\
\hline \multirow{2}{*}{2018} & Kentang Keriting & 1.855 .894 & 693.379 & 1.162 .515 & $62,64 \%$ \\
\cline { 2 - 6 } & Potato & 1.923 .090 & 980.586 & 942.504 & $49,01 \%$ \\
\hline
\end{tabular}

Berdasarkan tabel diatas, dapat diketahui bahwa penerapan metode EOQ pada pengendalian persediaan bahan baku di PT. Surya Indah Food Multirasa layak untuk diterapkan. Karena dengan menggunakan metode EOQ, perusahaan dapat lebih menghemat biaya untuk persediaan bahan baku khususnya bahan baku potato dan kentang keriting.

\section{Perhitungan Safety Stock}

Besarnya nilai safety stock diketahui dengan menggunakan perhitungan analisis penyimpangan. PT. Surya Indah Food Multirasa menentukan batas toleransi yang masih bisa diterima yaitu sebesar 5\% dan service ratio nya 95\% sehingga faktor pengamannya adalah 1,65. Berikut adalah perhitungan standar deviasi bahan baku Potato dan Kentang Keriting:

Tahun 2016

$$
\begin{array}{lll}
\text { Satndar Deviasi Kentang Keriting } & =\sqrt{\frac{3.656,25}{12}}=17,45530 \\
\text { Standar Deviasi Potato } & =\sqrt{\frac{20.641,66667}{12}}=41,47456
\end{array}
$$

Tahun 2017

$$
\begin{array}{lll}
\text { Satndar Deviasi Kentang Keriting } & =\sqrt{\frac{5.816,6667}{12}}=22,01641 \\
\text { Standar Deviasi Potato } & =\sqrt{\frac{25.822,91667}{12}}=46,38868
\end{array}
$$

Tahun 2018

$$
\begin{array}{lll}
\text { Satndar Deviasi Kentang Keriting } & =\sqrt{\frac{7191,6667}{12}} & =24,48072 \\
\text { Standar Deviasi Potato } & =\sqrt{\frac{27.522,9}{12}} & =47,8913
\end{array}
$$

Berikut merupakan perhitungan safety stock pada persediaan bahan baku Potato dan Kentang Keriting:

$$
\begin{array}{ll}
\text { Safety Stock Potato Tahun } 2016 & =\sigma \times \mathrm{Z} \\
& =41.475 \times 1,65 \\
& =68 \mathrm{~kg} \\
& =\sigma \times \mathrm{Z} \\
& =46.389 \times 1,65 \\
& =77 \mathrm{~kg} \\
\text { Safety Stock Potato Tahun } 2017 & =\sigma \times \mathrm{Z} \\
& =47.891 \times 1,65 \\
\text { Safety Stock Potato Tahun 2018 } & =79 \mathrm{~kg} \\
\text { Safety Stock Kentang Keriting Tahun } 2016 & =\sigma \times \mathrm{Z} \\
& =17.455 \times 1,65 \\
& =29 \mathrm{~kg} \\
\text { Safety Stock Kentang Keriting Tahun } 2017 & =\sigma \times \mathrm{Z} \\
& =22.016 \times 1,65 \\
\text { Safety Stock Kentang Keriting Tahun } 2018 & =36 \mathrm{~kg} \\
& =24.480 \times 1,65 \\
& =40 \mathrm{~kg}
\end{array}
$$


Tabel 8. Perhitungan Reorder Point

\begin{tabular}{|c|c|c|c|c|c|c|}
\hline Tahun & Produk & $\mathbf{D}(\mathbf{K g})$ & $\begin{array}{c}\text { Q } \\
\text { (Perhari) }\end{array}$ & $\begin{array}{c}\text { Lead } \\
\text { Time (hari) }\end{array}$ & $\begin{array}{c}\text { Safety } \\
\text { Stock (Kg) }\end{array}$ & ROP (Kg) \\
\hline & & & $\frac{D}{340}$ & & & $\begin{array}{l}\text { Safety stock }+ \\
(\text { lead time } x Q)\end{array}$ \\
\hline \multirow{2}{*}{2016} & Kentang Keriting & 1.065 & 3,13 & 7 & 29 & 51 \\
\hline & Potato & 2.270 & 6,68 & 7 & 68 & 115 \\
\hline \multirow{2}{*}{2017} & Kentang Keriting & 1.100 & 3,24 & 7 & 36 & 59 \\
\hline & Potato & 2.345 & 6,90 & 7 & 77 & 125 \\
\hline \multirow{2}{*}{2018} & Kentang Keriting & 1.210 & 3,56 & 7 & 40 & 65 \\
\hline & Potato & 2.405 & 7,07 & 7 & 79 & 129 \\
\hline
\end{tabular}

Berdasarkan tabel diatas, dapat diketahui jumlah produk perhari yang diperlukan (Q) diperoleh dari permintaan pertahun (D) dibagi dengan jumlah hari aktif dalam satu tahun di PT. Surya Indah Food Multirasa adalah 340 hari. Dengan adanya reorder point berdasarkan metode EOQ maka diharapkan perusahaan tidak akan mengalami kekurangan maupun kelebihan bahan baku ketika akan melakukan proses produksi.

\section{Perhitungan Maximum Inventory}

Tabel 9. Perhitungan Maximum Inventory

\begin{tabular}{ccccc}
\hline \multirow{2}{*}{ Tahun } & Produk & Safety Stock $(\mathbf{K g})$ & EOQ $(\mathbf{K g})$ & Maximum Inventory $(\mathbf{K g})$ \\
\hline \multirow{2}{*}{2016} & & & (EOQ + Safety Stock $)$ \\
\hline \multirow{2}{*}{2017} & Kentang Keriting & 29 & 213 & 242 \\
\cline { 2 - 5 } & Potato & 68 & 321 & 390 \\
\cline { 2 - 5 } & Kentang Keriting & 36 & 229 & 265 \\
\cline { 2 - 5 } 2018 & Potato & 77 & 344 & 421 \\
\cline { 2 - 5 } & Kentang Keriting & 40 & 260 & 301 \\
\cline { 2 - 5 } & Potato & 79 & 366 & 445 \\
\hline
\end{tabular}

Tabel 10. Perkiraan Kapasitas Gudang

\begin{tabular}{ccccccc}
\hline & $\begin{array}{c}\mathbf{P} \\
(\mathbf{m})\end{array}$ & $\begin{array}{c}\mathbf{L} \\
(\mathbf{m})\end{array}$ & $\begin{array}{c}\text { Luas } \\
\left(\mathbf{m}^{2}\right)\end{array}$ & $\begin{array}{c}\text { Tumpukan } \\
\text { Maksimal }\end{array}$ & $\begin{array}{c}\text { Rata-Rata } \\
\text { Maximum } \\
\text { Inventory }(\mathbf{K g})\end{array}$ & Kebutuhan luas gudang $\left(\mathbf{m}^{2}\right)$ \\
\hline Luas Gudang & 28 & 12 & 336 & & & \\
\hline Luas Rak 1 & 3,6 & 0,7 & 2,52 & & \\
\hline (a) & Dikali 3 set & 7,56 & & \\
\hline Luas Rak 2 & 2,4 & 0,7 & 1,68 & & \\
\hline (b) & Dikali 3 set & 5,04 & & \\
\hline Total luas rak & $(\mathbf{a}) \mathbf{x}(\mathbf{b})$ & 12,6 & & \\
\hline $\begin{array}{c}\text { Ukuran satu pack BB } \\
\text { Kentang Keriting }\end{array}$ & 0,6 & 0,4 & 0,240 & $5(@ 5 \mathrm{~kg})$ & 269 & 4,02 \\
\hline $\begin{array}{c}\text { Ukuran satu pack BB } \\
\text { Potato }\end{array}$ & 0,6 & 0,4 & 0,240 & $5(@ 5 \mathrm{~kg})$ & 418 & \\
\hline
\end{tabular}

Berdasarkan tabel diatas diketahui penggunaan gudang penyimpanan menggunakan perhitungan maximum inventory tidak melebihi kapasitas kemampuan gudang. Luas gudang penyimpanan PT. Surya Indah Food Multirasa ialah sebesar $336 \mathrm{~m}^{2}$. Penyimpanan bahan baku potato dan kentang keriting disediakan rak penyimpanan khusus dengan luas keseluruhan $12,6 \mathrm{~m}^{2}$. Sedangkan kebutuhan luas gudang sesuai perhitungan maximum inventory hanya $8,33 \mathrm{~m}^{2}$. 


\section{Penggunaan Peramalan untuk Menentukan EOQ tahun 2019}

Perhitungan dengan metode EOQ sebelumnya dilakukan menggunakan data permintaan bahan baku mulai tahun 2016 hingga 2018, dimana hasil perhitungan yang diperoleh merupakan perhitungan EOQ untuk tahun 2016 sampai 2018. Agar dapat diketahui nilai EOQ pada tahun 2019, maka perlu dilakukan metode peramalan data permintaan bahan baku PT. Surya Indah Food Multirasa pada tahun 2019 menggunakan model Winter's sehingga dapat dilakukan perhitungan EOQ pada tahun 2019. Berikut merupakan gambar grafik permintaan bahan baku aktual terhadap hasil peramalan selama tahun 2016-2019 pada bahan baku potato dan kentang keriting:

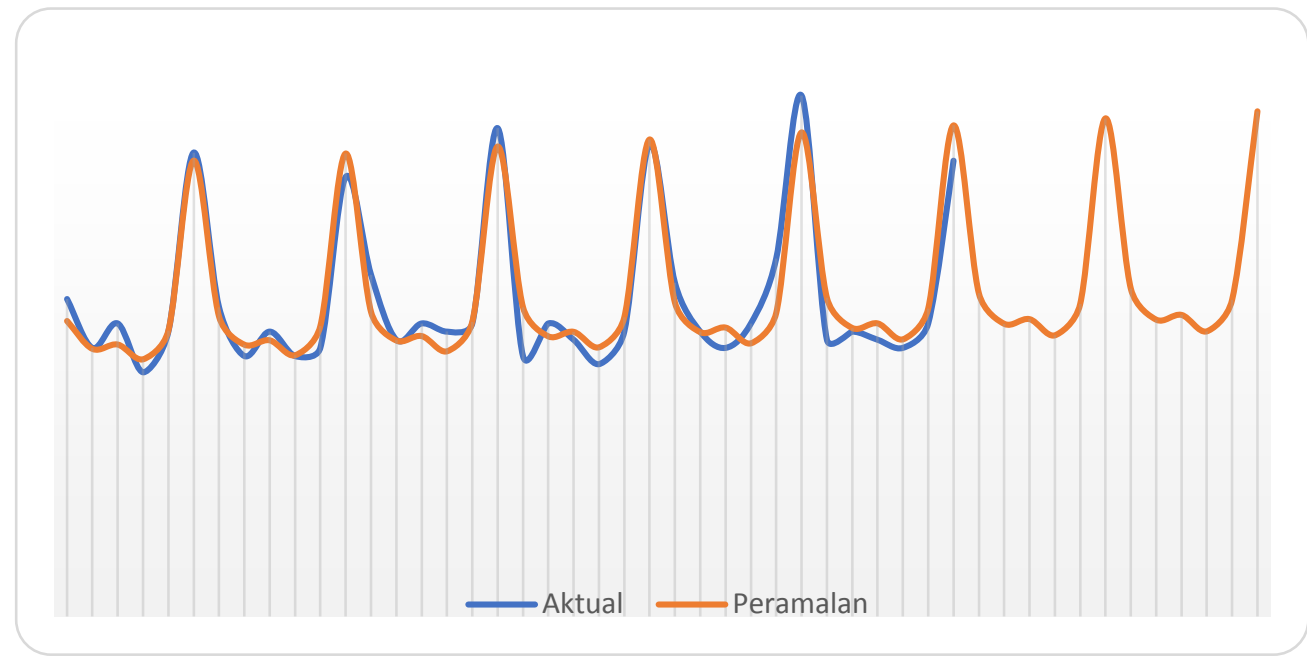

Gambar 1. Grafik Permintaan Bahan Baku Potato

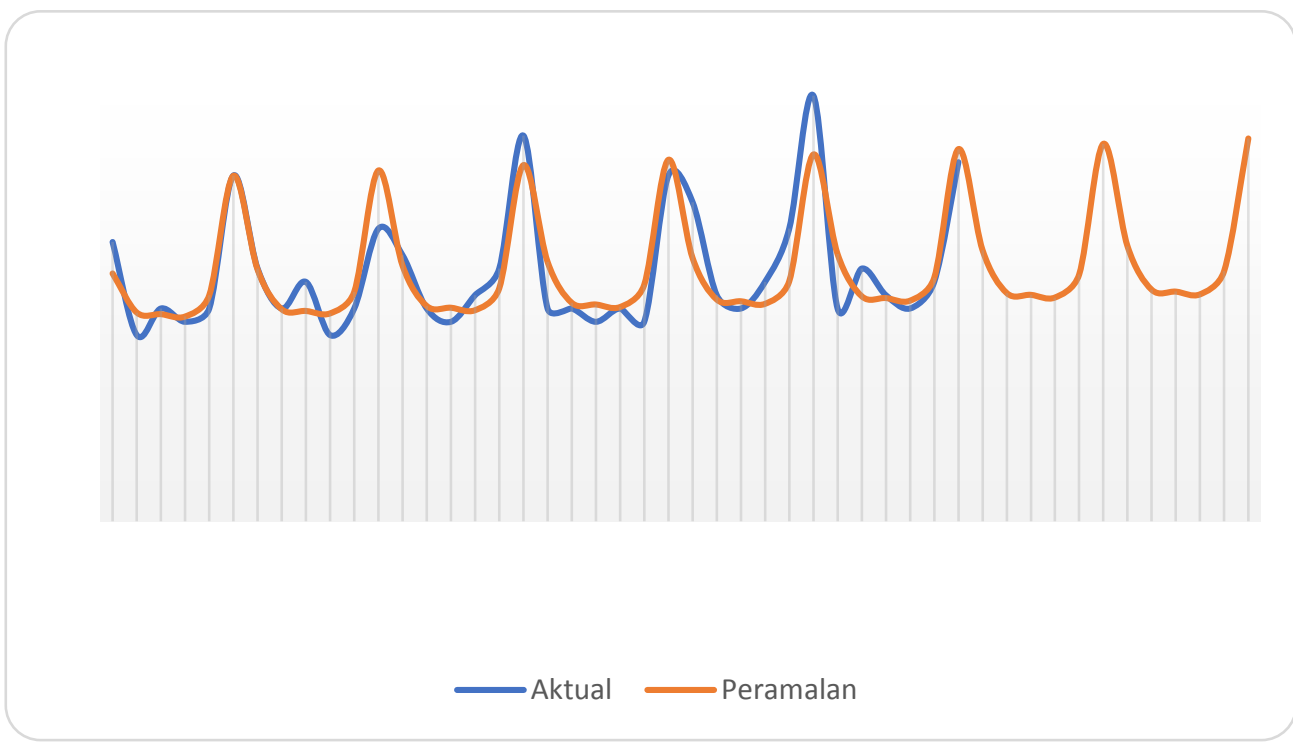

Gambar 2. Grafik Permintaan Bahan Baku Kentang Keriting

Hasil peramalan data permintaan bahan baku potato dan kentang keriting mendapatkan nilai MAPE (Mean Average Percentage Error) $<10 \%$, yaitu pada bahan baku potato 5,35 \% dan kentang keriting 8,03 \%. Menurut Halimi (2013) nilai MAPE yang memiliki hasil < $10 \%$ menunjukkan kemampuan peramalan yang sangat baik. Sehingga pada hasil ramalan permintaan bahan baku potato dan kentang keriting pada tahun 2019 dapat digunakan untuk mendapatkan nilai EOQ tahun 2019. 
Tabel 11. Perhitungan EOQ tahun 2019

\begin{tabular}{|c|c|c|c|c|c|c|}
\hline Tahun & Produk & $\begin{array}{c}\text { Kebutuhan Bahan } \\
\text { Baku per Tahuun } \\
\text { (Kg) }\end{array}$ & $\begin{array}{c}\text { Biaya } \\
\text { Penyimpanan } \\
\text { per Unit (Rp) }\end{array}$ & $\begin{array}{c}\text { Biaya } \\
\text { Pemesanan } \\
(\mathbf{R p})\end{array}$ & $\begin{array}{c}\text { Jumlah } \\
\text { Pesanan } \\
\text { (Kg) }\end{array}$ & $\begin{array}{c}\text { Frekuensi } \\
\text { (kali) }\end{array}$ \\
\hline & & & & & EOQ = & $\boldsymbol{D}$ \\
\hline & & D & H & $\mathbf{S}$ & $\sqrt{\frac{\text { LADS }}{H}}$ & $f=\overline{E O Q}$ \\
\hline \multirow{2}{*}{2019} & $\begin{array}{l}\text { Kentang } \\
\text { Keriting }\end{array}$ & 1.192 & $2.665,63$ & 74.529 & 258 & 5 \\
\hline & Potato & 2.481 & $2.682,26$ & 74.529 & 371 & 7 \\
\hline
\end{tabular}

Berdasarkan hasil perhitungan EOQ menggunakan data hasil peramalan, diketahui nilai EOQ bahan baku potato pada tahun 2019 meningkat sebesar 1,366\% dari tahun 2018 yaitu sebanyak $371 \mathrm{~kg}$ dalam sekali pesan dengan frekuensi per tahun yang sama yaitu sebanyak 7 kali. Hal itu terjadi dikarenakan pola permintaan bahan baku potato memiliki tren yang naik dari tahun ke tahun. Sedangkan pada bahan baku kentang keriting mengalami penurunan sebesar $0,769 \%$ dibanding tahun 2018 yaitu sebanyak $260 \mathrm{~kg}$ per pesan menjadi $258 \mathrm{~kg}$ per pesan pada tahun 2019, dengan frekuensi yang masih sama yaitu sebanyak 5 kali dalam setahun. Hal itu dikarenakan tren permintaan bahan baku kentang keriting terjadi kenaikan dan penurunan ditahun sebelumnya, sehingga peramalan yang dilakukan menghasilkan hasil yang sesuai dengan data aktual tahun-tahun sebelumnya.

\section{Simpulan}

Penggunaan metode EOQ pada pengendalian persediaan bahan baku potato dan kentang keriting di PT. Surya Indah Food Multirasa dapat menekan biaya total persediaan sehingga biaya yang dikeluarkan oleh PT. Surya Indah Food Multirasa menjadi lebih hemat. Penghematan bahan baku potato mulai tahun 2016 sampai 2018 ialah sebesar 46\%, 48\% dan 49\%, sedangkan pada bahan baku kentang keriting ialah sebesar 60\%, 61\% dan 63\%. Dengan menggunakan metode EOQ dapat diketahui nilai persediaan pengaman (SS) dan titik pemesanan kembali (ROP) sehingga bahan baku potato dan keriting akan tersedia secara tepat dan tidak mengalami kekurangan persediaan.

Persediaan pengaman (safety stock) pada bahan baku potato mulai dari tahun 2016 sampai 2018 ialah sebesar 68, 77, dan $79 \mathrm{~kg}$. Sedangkan pada bahan baku kentang keriting ialah sebesar 29, 36 dan $40 \mathrm{~kg}$. Dengan disediakannya persediaan pengaman (safety stock), maka persediaan bahan baku potato dan kentang keriting tidak sampai terjadi kekurangan bahan baku. Titik pemesanan kembali (reorder point) pada bahan baku potato mulai dari tahun 2016 sampai 2018 ialah sebesar 115, 125 dan $129 \mathrm{~kg}$. Sedangkan pada bahan baku kentang keriting ialah sebesar 51,59, dan $65 \mathrm{~kg}$. Dengan nilai titik pemesanan kembali tersebut, maka perusahaan dapat melakukan pemesanan bahan baku potato dan kentang keriting dengan tepat dan dapat datang sesuai waktu yang diperkirakan. Sehingga tidak sampai terjadi keterlambatan bahan baku potato dan kentang keriting. Penggunaan model Winter's dalam melakukan peramalan data bahan baku potato dan kentang keriting mendapatkan nilai MAPE < $10 \%$ yang menunjukkan kemampuan peramalan yang sangat baik. Sehingga dapat menjadi acuan perusahaan menentukan persediaan di tahun yang akan datang.

\section{Daftar Pustaka}

Assauri, Sofjan. 2008. Manajemen Produksi dan Operasi. Jakarta: FEUI.

Direktorat Jenderal Industri Agro. 2018. Kinerja Industri Agro Semester 1 Tahun 2018. Agro.Kemenperin.go.id.

Darmawan, G. A., Wayan C., Ni Nyoman Y. 2015. Penerapan economic order quantity (EOQ) dalam pengelolaan persediaan bahan baku tepung pada Usaha Pia Ariawan di Desa Banyuning Tahun 2013. E-Journal Bisma Universitas Pendidikan Ganesha, 3 (1): 1-10.

Halimi R, W Anggraeni dan R Tyasnurita. 2013. Pembuatan Aplikasi Peramalan Jumlah Permintaan Produk dengan Metode Time Series Exponential Smoothing Holts Winter di Pt. Telekomunikasi Indonesia Tbk. Jurnal Teknik POMITS. 1(1): 1-6.

Herjanto, Eddy. 2015. Manajemen Operasi Edisi Ketiga. Jakarta: Grasindo.

Indroprasto dan Erma S. 2012. Analisis pengendalian persediaan produk dengan metode EOQ menggunakan algoritma genetika untuk mengefisiensikan biaya persediaan. Jurnal Teknik ITS,1 (1): 305-309.

Ma'arif, M S dan H Tanjung. 2003. Manajemen Operasi. Jakarta: Grasindo.

Mahatmyo, Atyanto. 2014. Sistem Informasi Akuntansi Suatu Pengantar. Yogyakarta: Deepublish.

Mardiyanto, H. 2008. Inti Sari Manajemen Keuangan. Jakarta: Grasindo. 
Margaretha, Farah, 2007, Manajemen Keuangan bagi Industri Jasa, Grasindo : Jakarta

Nasution, A. H., dan Prasetyawan, Y, (2008), Perencanaan \& Pengendalian Produksi, Edisi Pertama, Graha Ilmu : Yogyakarta.

Rentra N, Djoko H, Nurseto S. 2013. Analisis Pengendalian Persediaan Bahan Baku Rokok Pada PT. Gentong Gotri Semarang Guna Meningkatkan Efisiensi Biaya Persediaan. Journal Of Social And Politic Tahun 2013. 2 (4): 1-8.

Sampeallo, Y Gessong. 2012. Analisis Pengendalian Persediaan Pada UD. Bintang Furniture Sangasanga. Jurnal Eksis. 8(1): 2001-2181.

Siwi, Max O. 2012. Analisis Pengendalian Persediaan Bahan Baku Dengan Metode EOQ Pada Produk Obat Anti Nyamuk Bakar Manguni. Jurnal Ilmu Administrasi. 8(1): 1-7.

Sugiyono, 2009, Metode Penelitian Kuantitatif, Kualitatif dan R\&D, Bandung : Alfabet. 